\title{
Y- $\alpha^{\prime}-$ サイアロンの熱伝導率及び機械特性に及ぼす Sr 添加効果
}

\author{
平井岳根 $\cdot$ 村尾俊裕 ${ }^{* \dagger} \cdot$ Manuel E. Brito** ·鳥山素弘*** . 神崎修三** \\ (株)いすが中央研究所, 252-8501 藤沢市土棚 8 \\ *(株)いすがセラミックス研究所, 252-8501 藤沢市土棚 8 \\ **産業技術総合研究所シナジーマテリアル研究センター，463-8687 名古屋市守山区下志段味字穴ヶ洞 2268-1 \\ ***産業技術総合研究所, 305-8561 つくば市東 1-1-1
}

\section{Effect of Sr Addition on Thermal Conductivity and Mechanical Properties of $Y$ - $\alpha^{\prime}$-SiAION}

Takene HIRAI, Toshihiro MURAO, ${ }^{* \dagger}$ Manuel E. BRITO, ${ }^{* *}$ Motohiro TORIYAMA*** and Shuzo KANZAKI**

\author{
Isuzu Advanced Engineering Center Co., Ltd., 8, Tsuchidana, Fujisawa-shi 252-8501 \\ *Isuzu Ceramics Research Institute Co., Ltd., 8, Tsuchidana, Fujisawa-shi 252-8501 \\ **Synergy Materials Research Center, National Institute of Advanced Industrial Science and Technology, \\ 2268-1, Shimo-shidami, Moriyama-ku, Nagoya-shi 463-8687 \\ ***National Institute of Advanced Industrial Science and Technology, 1-1-1, Higashi, Tsukuba-shi 305-8561
}

\begin{abstract}
$\alpha^{\prime}$-SiAlON containing $\mathrm{Sr}$, having a large ionic radius, was obtained by hot-pressing. Sr was accommodated in $\alpha^{\prime}$-SiAlON in conjunction with Y. The effect of adding Sr to Y- $\alpha^{\prime}$-SiAlON on thermal conductivity and mechanical properties was studied. Thermal conductivity decreased from $11.9 \mathrm{~W} / \mathrm{m} \cdot \mathrm{K}$ to $6.2 \mathrm{~W} / \mathrm{m} \cdot \mathrm{K}$ with increasing addition of $\mathrm{Sr}$, due to increasing of phonon scattering both in the lattice and at the grain boundary. Bending strength increased from $460 \mathrm{MPa}$ to $860 \mathrm{MPa}$ with increasing addition of $\mathrm{Sr}$. The increase in bending strength can be associated with grain size refinement and fracture toughness. Fracture toughness also increased with increasing addition of Sr.

[Received February 7, 2002; Accepted May 21, 2002]
\end{abstract}

Key-words : Strontium, SiAlON, Thermal Conductivity, Ionic radius, Lattice deffect

\section{1. 緒 言}

窒化ケイ素の固溶体であるサイアロンセラミックスは, 窒化 ケイ素と比較して低熱伝導性を示すことが知られている1) 4). サイアロンには窒化ケイ素と同様に， $\alpha$ 型（ $\alpha^{\prime}-$ サイアロン）と $\beta$ 型（ $\beta^{\prime}$-サイアロン）の 2 種類の結晶形が存在する． $\beta^{\prime}$-サイ アロンは $\beta-\mathrm{Si}_{3} \mathrm{~N}_{4}$ と同じ結晶構造を持ち, $\mathrm{Si}$ のサイトと $\mathrm{N}$ の サイトそれぞれに，Al と O が置換固溶した化合物である5). 一方 $\alpha^{\prime}$-サイアロンは, $\alpha-\mathrm{Si}_{3} \mathrm{~N}_{4}$ と同じ結晶構造を持ち, $\mathrm{Al}$ と $\mathrm{O}$ が置換固溶し，かつ, $\mathrm{Si}_{12} \mathrm{~N}_{16}$ 単位格子中に 2 個存在する格 子間空隙に希土類元素, ランタノイド元素等が侵入型固溶した 化合物である6). また，上記の $\beta^{\prime}$-サイアロンと $\alpha^{\prime}$-サイアロン が共存する化合物（ $\alpha^{\prime} / \beta^{\prime}$-サイアロン）も存在する。これらサ イアロンが低熱伝導性を示すのは，前述の固溶により， $\mathrm{Si}_{3} \mathrm{~N}_{4}$ 格子中に点欠陥が生じフォノンが散乱されるためである7). し たがって, 固溶量の増加に伴って熱伝導率は低下する1),2)が, 機械特性も低下する ${ }^{8)}$ ため, 遮熱構造部材への適用を検討する 場合, 単純に固溶量を増やすことはできない。

$\alpha^{\prime}$-サイアロンと $\beta^{\prime}$-サイアロンを比較すると, 同じ $\mathrm{O}$ 置換量 では $\alpha^{\prime}$-サイアロンの方が低熱伝導性を示す。これは， $\alpha^{\prime}$-サイ アロン結晶が前述のように格子間空隙に元素が侵入固溶してい ることから結晶格子が昰み, 粒内でフォノンがより散乱されて いるためと考えられる. しかし， $\alpha^{\prime}$-サイアロンの一般式 $\mathrm{M}_{x}(\mathrm{Si}$, $\mathrm{Al})_{12}(\mathrm{O}, \mathrm{N})_{16}$ において，その単相生成領域は $\mathrm{M}=\mathrm{Y}$ を例にと ると， $0.33<x<0.67$ 狭い範囲に限定される ${ }^{9), 10)} . x$ 值がそれ 以下では前述の $\alpha^{\prime} / \beta^{\prime}$-サイアロンとなる．したがって，熱伝導 率を低下させるために固溶量を大幅に増加させることはできな

†現在：サソールジャパン(株)，104-6591 東京都中央区明石町 $8-1$

Now with Sasol Japan Co., Ltd., 8-1, Akashi-cho, Chuo-ku, Tokyo 104-6591
い. $\alpha^{\prime}$-サイアロン粒内で更にフォノン散乱を増加させるため に，より大きいイオン半径を持つ元素を導入することが考えら れる. 侵入固溶して $\alpha^{\prime}$-サイアロンを形成する元素はそのイオ ン半径が $0.1 \mathrm{~nm}$ 以下とされている11,12)。しかしながら, 単独 では $\alpha^{\prime}$-サイアロンを形成しない Ce（イオン半径 : $0.103 \mathrm{~nm}$ ) が Y と同時添加することによって $\alpha^{\prime}$-サイアロン格子内に一部 固溶することが報告されている13) 16)。 また, Hwang らは $\mathrm{Sr}$ (イオン半径 : $0.113 \mathrm{~nm}$ ) が同様に Y, Ca と同時添加すること によって $\alpha^{\prime}$-サイアロン格子内に固溶することを報告してい る17)。しかし，これまでそれらの熱特性，機械特性について 明らかにされてはいない。

本研究では， $\alpha^{\prime}$-サイアロンの熱伝導率をより低下させるた め, Sr と Y を組み合わせて添加することによって $\mathrm{Y}-\mathrm{Sr}$ 含有 $\alpha^{\prime}$-サイアロン焼結体を作製し, Srの添加量が焼結体の微構造 と特性に及ぼす影響について検討を行った。

\section{2. 実験方法}

出発原料として $\alpha-\mathrm{Si}_{3} \mathrm{~N}_{4}$ (宇部興産製, $\mathrm{SN}-\mathrm{E} 10$ ), $\mathrm{AlN}$ (ト クヤマ製，F), $\mathrm{Y}_{2} \mathrm{O}_{3}$ (北興化学工業製，純度 $99.9 \%$ ), $\mathrm{SrCO}_{3}$ （和光純薬工業製，純度 $99.9 \%$ ）を用いた， $\alpha^{\prime}$-サイアロンの一 般式 $\mathrm{M}_{x}(\mathrm{Si}, \mathrm{Al})_{12}(\mathrm{O}, \mathrm{N})_{16}$ において, 総侵入固溶量 $(x)$ を 0.5 一定として, $\mathrm{M}_{x}=\mathrm{Y} 0.50(\mathrm{Sr} 0), \mathrm{Y} 0.45 \mathrm{Sr} 0.05(\mathrm{Sr} 5), \mathrm{Y} 0.40 \mathrm{Sr} 0.10$ (Sr10), Y0.35Sr0.15(Sr15), Y0.30Sr0.20(Sr20) となるよう に, おのおの, 出発原料を所定量配合した.このとき, $\mathrm{Y}, \mathrm{Sr}$ のイオン価数はおのおの 3 価, 2 価として配合し, 窒化物原料 中に含まれる酸素量は補正した. 各試料の配合組成と化学式を 表 1 に示す。これら配合粉末にイソプロパノールを加えて窒化 ケイ素製ボールとともに窒化ケイ素製ポットに入れ，遊星ミル により $2 \mathrm{~h}$ 混合した，得られたスラリーはロータリーエバポ レーターを用いて溶媒を除去し, 更に $100^{\circ} \mathrm{C}$ 真空乾燥器で乾 
Table 1. Compositions of Powder Mixtures Studied

\begin{tabular}{lllllll}
\hline & \multicolumn{5}{c}{ Composition /mass\% } & \\
\cline { 2 - 5 } Specimens & $\mathrm{Si}_{3} \mathrm{~N}_{4}$ & $\mathrm{AlN}$ & $\mathrm{Y}_{2} \mathrm{O}_{3}$ & $\mathrm{SrCO}_{3}$ & Formula \\
\hline Sr0 & 73.99 & 16.68 & 9.33 & & $\mathrm{Y}_{0.50}\left(\mathrm{Si}_{9.54} \mathrm{Al}_{2.46}\right)\left(\mathrm{O}_{0.96} \mathrm{~N}_{15.04}\right)$ \\
Sr5 & 74.30 & 16.11 & 8.37 & 1.22 & $\mathrm{Y}_{0.45} \mathrm{Sr}_{0.05}\left(\mathrm{Si}_{9.62} \mathrm{Al}_{2.38}\right)\left(\mathrm{O}_{0.93} \mathrm{~N}_{15.07}\right)$ \\
Sr10 & 74.60 & 15.56 & 7.42 & 2.42 & $\mathrm{Y}_{0.40} \mathrm{Sr}_{0.10}\left(\mathrm{Si}_{9.69} \mathrm{Al}_{2.31}\right)\left(\mathrm{O}_{0.91} \mathrm{~N}_{15.09}\right)$ \\
Sr15 & 74.91 & 15.00 & 6.47 & 3.62 & $\mathrm{Y}_{0.35} \mathrm{Sr}_{0.15}\left(\mathrm{Si}_{9.77} \mathrm{Al}_{2.23}\right)\left(\mathrm{O}_{0.88} \mathrm{~N}_{15.12}\right)$ \\
Sr20 & 75.21 & 14.45 & 5.52 & 4.82 & $\mathrm{Y}_{0.30} \mathrm{Sr}_{0.20}\left(\mathrm{Si}_{9.84} \mathrm{Al}_{2.16}\right)\left(\mathrm{O}_{0.86} \mathrm{~N}_{15.14}\right)$ \\
\hline
\end{tabular}

燥した後, 60 mesh のナイロンふるいを通して均一な混合粉末 とした.この混合粉末を BN で被覆した黒鉛型に充填し， 0.1 $\mathrm{MPa}$ の窒素中, $40 \mathrm{MPa}$ の加圧下, $1825^{\circ} \mathrm{C} て ゙ ~ 2 \mathrm{~h}$ ホットプレ スを行い，各焼結体を得た。

得られた焼結体について，水中のアルキメデス法による密度 測定, JIS R1602 の超音波パルス法によるヤング率測定, $\mathrm{CuK} \alpha$ 線を用いた粉末 $\mathrm{X}$ 線回折法（リガク製，ロータフレッ クスX 線回折装置 RD-RB）による結晶相同定, JIS R1601 に よる 4 点曲げ強度測定, JIS R1607 の圧子圧入法（IF 法）に よる破壊勒性測定を行った. 破壊勒性測定の際, 予龟裂発生起 点のビッカース圧痕を押込加重 $98 \mathrm{~N}$ で導入し, 同時に JIS R1610によるビッカース硬度の測定も行った．また，JIS R1611のレーザーフラッシュ法（真空理工製，レーザーフ ラッシュ法熱定数測定装置 TC-7000）による熱拡散率の測定 を行い, 熱伝導率を算出した，このとき, 密度は前述のアルキ メデス法の測定值を用い, 比熱容量は $670 \mathrm{~J} / \mathrm{kg} \cdot \mathrm{K}$ 一定とし た ${ }^{18)}$. 各焼結体の破断面を走査型電子顕微鏡（SEM；日本電 子製走査顕微鏡, JSM-5800）を用いて観察し, 微細組織観察 を透過型電子顕微鏡（TEM；日本電子製，JEM-2010F）を 用いて行った。 また，粒子の組成分析を TEM 付設の EDX (Noran 社製) を用いて行った。

\section{3. 結果及び考察}

表 2 に各焼結体の密度, ヤング率, 硬度を示す. 得られた焼 結体の密度は, 理論密度 $\left(3290 \sim 3300 \mathrm{~kg} / \mathrm{m}^{3}\right)$ から考えて十 分に緻密な焼結体であった．ここで理論密度は, $\mathrm{Si}_{3} \mathrm{~N}_{4} \quad(3180$ $\left.\mathrm{kg} / \mathrm{m}^{3}\right), \mathrm{AlN}\left(3260 \mathrm{~kg} / \mathrm{m}^{3}\right), \mathrm{Y}_{2} \mathrm{O}_{3}\left(5030 \mathrm{~kg} / \mathrm{m}^{3}\right), \mathrm{SrO}(5010$ $\left.\mathrm{kg} / \mathrm{m}^{3}\right)$ の重量平均とした. Srを添加していない $\mathrm{Y}-\alpha^{\prime}$-サイア ロン（Sr0）と比較して，その他の $\mathrm{Sr}$ を添加した 4 試料のヤ ング率, 硬度にほとんど変化がないことから, 今回得られた焼 結体はいずれも $\alpha^{\prime}$-サイアロンの特徵である高弾性, 高硬度の 特性を持つ焼結体であることが分かった.

図 1 に各焼結体の $\mathrm{X}$ 線回折パターンを $\alpha-\mathrm{Si}_{3} \mathrm{~N}_{4}, \beta-\mathrm{Si}_{3} \mathrm{~N}_{4}$ の主 なピーク位置とともに示す. 図中, (○), (○) で示したピー クは $\alpha-\mathrm{Si}_{3} \mathrm{~N}_{4}, \beta-\mathrm{Si}_{3} \mathrm{~N}_{4}$ のピーク位置から低角側にシフトしてい ることから打の抢の， $\alpha^{\prime}$-サイアロン， $\beta^{\prime}$-サイアロンと同定さ れる. Sr0では $\alpha^{\prime}$-サイアロンのピークのみが観察されたのに 対し，Srを添加することによって $\beta^{\prime}$-サイアロンのピークと （覀）で示す同定できない相が出現した.

得られた焼結体の破断面の観察結果を図 2 に示す．Sr0では 粒径約 $1 \mu \mathrm{m}$ の等軸状粒子のみから構成されていたのに対し, その他の焼結体では Srを添加することによって第 2 相と思わ れるアスペクト比の高い異方性粒子が出現した. 図 1 で示し た X 線回折パターンと総合すると，図 2 で観察された等軸状 粒子は $\alpha^{\prime}$-サイアロンであり, 異方性粒子は $\beta^{\prime}$-サイアロン，も しくは同定できなかった相と推定される．また粒子サイズは等 軸状粒子，異方性粒子ともに Sr 添加量の増加に伴って小さく
Table 2. Physical Properties of Samples

\begin{tabular}{llll}
\hline Specimens & $\rho / 10^{3} \mathrm{~kg} \cdot \mathrm{m}^{-3}$ & $\mathrm{E} / \mathrm{GPa}$ & $\mathrm{Hv} / \mathrm{GPa}$ \\
\hline Sr0 & 3.29 & 329 & 21.3 \\
Sr5 & 3.30 & 322 & 21.1 \\
Sr10 & 3.30 & 326 & 21.7 \\
Sr15 & 3.31 & 326 & 20.7 \\
Sr20 & 3.29 & 317 & 21.4 \\
\hline
\end{tabular}

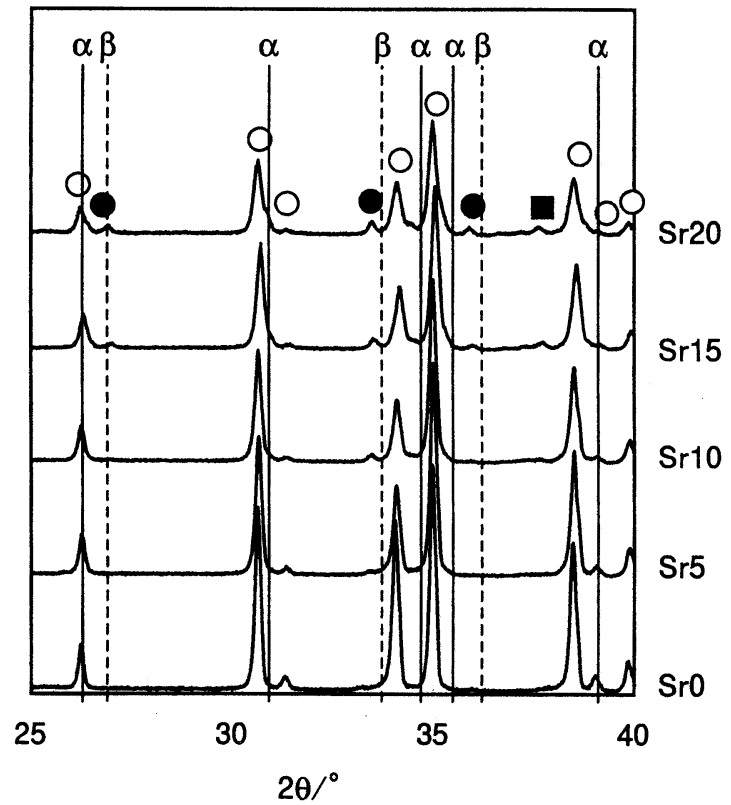

Fig. 1. X-ray diffraction patterns of Sr added $\mathrm{Y}-\alpha^{\prime}-\mathrm{SiAlON}$. $0 \alpha^{\prime}$-SiAlON, $\beta^{\prime}$-SiAlON, $\mathbf{u}$ unidentified phase

なった.この粒子サイズの微細化は等軸状粒子, 異方性粒子双 方が互いに粒成長を阻害しあったためと考える.

図 3 に Sr20 の TEM 観察像を示す. 図 2 で示したように $\alpha^{\prime}$-サイアロンの特徵的な等軸状粒子がマトリックス粒子とし て観察されたのに対し，それとは明らかにコントラストの異な る粒子も観察された．図 3 で観察されたマトリックスの等軸 状粒子とコントラストの異なる異方性粒子それぞれのEDXに よる元素分析結果を図 4 に示す. 分析結果より，等軸状粒子か らはサイアロン結晶格子の骨格を構成する $\mathrm{N}, \mathrm{O}, \mathrm{Al}, \mathrm{Si}$ のほか に $\mathrm{Y}, \mathrm{Sr}$ が検出された.これより等軸状粒子は $\alpha^{\prime}$-サイアロン であり, 添加した Sr は Y とともに粒内に固溶したことが確認 された，一方，異方性粒子からはサイアロン結晶格子の骨格を 形成する元素のほかには，Srのみが検出された。 また，等軸 状粒子と比較して $\mathrm{Al}$ のピーク強度が高かった， $\beta^{\prime}$-サイアロン からは $\mathrm{Sr}$ は検出されないのでこの分析した粒子は図 1 に示し 


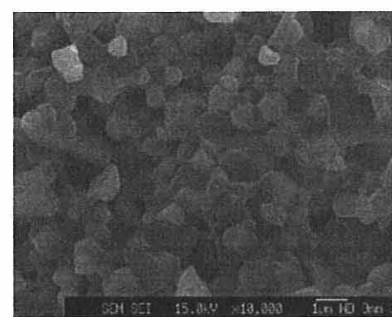

(a) $\operatorname{Sr} 0$

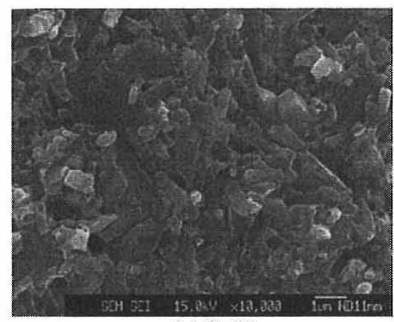

(c) $\mathrm{Sr} 10$

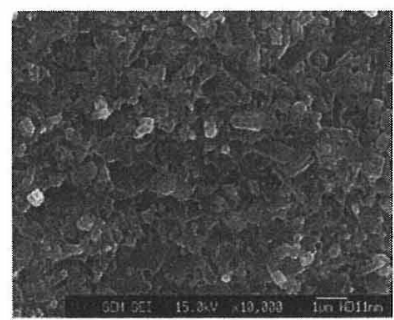

(e) $\operatorname{Sr} 20$

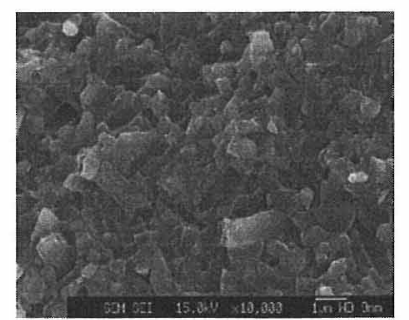

(b) Sr5

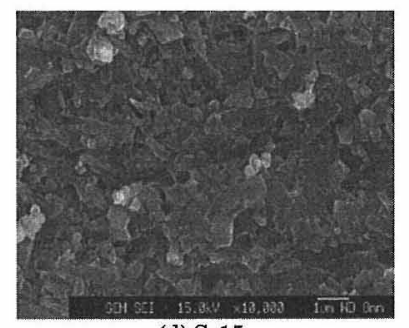

(d) Sr15
Fig. 2. SEM photographs of fracture surface of Sr added Y- $\alpha^{\prime}$ SiAlON.

(a) Sr0, (b) Sr5, (c) Sr10, (d) Sr15, (e) Sr20.



Fig. 3. TEM micrograph of Sr added Y- $\alpha^{\prime}-$ SiAlON (Sr20) analyzed. (a) Equiaxied grain and (b) anisotropic grain

た同定できなかった相と思われる。この未知相は $\mathrm{SrSi}_{3-x}$ $\mathrm{Al}_{x} \mathrm{O}_{1+{ }_{x}} \mathrm{~N}_{4-x}$ で表されるメリライトの固溶体 ${ }^{19)}$ 21) 等, $\mathrm{SrO}$,
$\mathrm{Si}_{3} \mathrm{~N}_{4}, \mathrm{Al}_{2} \mathrm{O}_{3}$ の化合物が考えられる. 以上より, 添加した $\mathrm{Sr}$ は $\alpha^{\prime}$-サイアロン粒内には全量は固溶せず, 固溶しなかった $\mathrm{Sr}$ は図 4 (b) に該当する $\alpha^{\prime}$-サイアロン組成より $\mathrm{Al}$ が高濃度な ( $\mathrm{Sr}, \mathrm{Si}, \mathrm{Al}, \mathrm{O}, \mathrm{N})$ 化合物を形成したか，まるいはガラス相 （粒界相）を形成したものと思われる，詳細についてはさらな る検討を要する。

$\mathrm{Sr}$ 添加量と 4 点曲げ強度, 熱伝導率の関係を図 5 に示す. 侵入固溶元素が $\mathrm{Y}$ のみの $\mathrm{Sr} 0$ で $11.9 \mathrm{~W} / \mathrm{m} \cdot \mathrm{K}$ であった熱伝導 率は，Srを添加することによって Sr10で急激に低下し，Sr15


$462 \mathrm{MPa}$ であった 4 点曲げ強度は $\mathrm{Sr}$ 添加に伴い上昇し, Sr10, Sr15 で約860 MPa を示した. Sr 添加量をこれ以上増や すと低下し, Sr20で655 MPa となった。

熱伝導率低下の理由として，第一に Srの $\alpha^{\prime}$-サイアロン粒内 への固溶が粒内でのフォノン散乱を増加させ，熱伝導率低下に 寄与したことが考えられる．第二に粒子サイズが小さくなった ことによる粒界の増加に起因するフォノン散乱の増加, 第 2 相出現による異相間の粒界でのフォノン散乱, 粒界相自体の フォノン散乱効果が考えられる。 また第 2 相が $\alpha^{\prime}$-サイアロン より低熱伝導性であれば，複合効果による熱伝導率の低下も考 えられる。

本研究で検討した焼結体の 4 点曲げ強度は, 図 4 に示した ように Sr 添加量の増加とともに上昇して極大值を示した後, 低下した。強度が上昇した一因として図 2 で示した粒子サイ ズの微細化が挙げられる. Sr 添加量と 4 点曲げ強度, 破壊鞢 性值の関係を図 6 に示す. $\mathrm{Sr} 0$ で $3.0 \mathrm{MPa} \cdot \mathrm{m}^{1 / 2}$ であった破壊 勒性值は, $\mathrm{Sr}$ 添加に伴い上昇し $\mathrm{Sr} 10, \mathrm{Sr} 15$ で約 $4.5 \mathrm{MPa} \cdot \mathrm{m}^{1 / 2}$ を示した. Sr 添加量をこれ以上増加させると低下し, Sr20で $3.6 \mathrm{MPa} \cdot \mathrm{m}^{1 / 2}$ となり強度と同様な傾向を示した，これより， 強度向上の他の要因として破壊勒性值の向上が挙げられる.こ の破壊䩲性值の向上は異方性粒子の出現による亀裂の屈曲や枝 分かれが促進されたためと思われる，また，この亀裂の屈曲や 枝分かれが促進されるためには比較的共有結合性の強い結晶相 （サイアロン）とイオン結合性の強い粒界ガラス相からなる複 合体で粒界相の部分を主に亀裂が進展することが必要であ る22). 図 2 の破面観察より, Sr 添加量の増加に伴い粒界破壊 が多くなると同時に柱状粒子が出現した．この結果と前記に示 した理由により破壊勒性が向上したと考える．粒界破擐が多く なったのは, 粒界ガラス相生成により粒界が弱くなったためと 考えられる．この粒界ガラス相が多くなりすぎた結果として龟 裂の屈曲や枝分かれが起こりにくくなり，Sr20では破壊勒性 值， 4 点曲げ強度が低下したものと思われる。

\section{4. 結 論}

Y- $\alpha^{\prime}$-サイアロンの Y を一部 Srk置換することによって Sr を含有する $\alpha^{\prime}$-サイアロンを得た．Sr 添加によって熱伝導率が 低下すると同時に機械特性が向上し, 熱伝導率の最低值として $6.2 \mathrm{~W} / \mathrm{m} \cdot \mathrm{K}, 4$ 点曲げ強度の最高值として $866 \mathrm{MPa}$ を得た。熱 伝導率低下の原因として, 粒界, 粒内双方のフォノン散乱の増 加と考察し, 機械特性向上の要因として, 粒子サイズの微細 化, 及び異方性粒子の出現と粒界破壞による亀裂の屈曲, 枝分 かれによるものと推定した。

謝辞 本研究は経済産業省産業技術環境局が推進する産業 技術基盤研究開発プロジェクト「シナジーセラミックスの研究開 発」の一環として, シナジーセラミックス研究体に属する著者ら によって行われたものである. 研究の一部は本プロジェクトの下 にファインセラミックス技術研究組合が新エネルギー・産業技術 

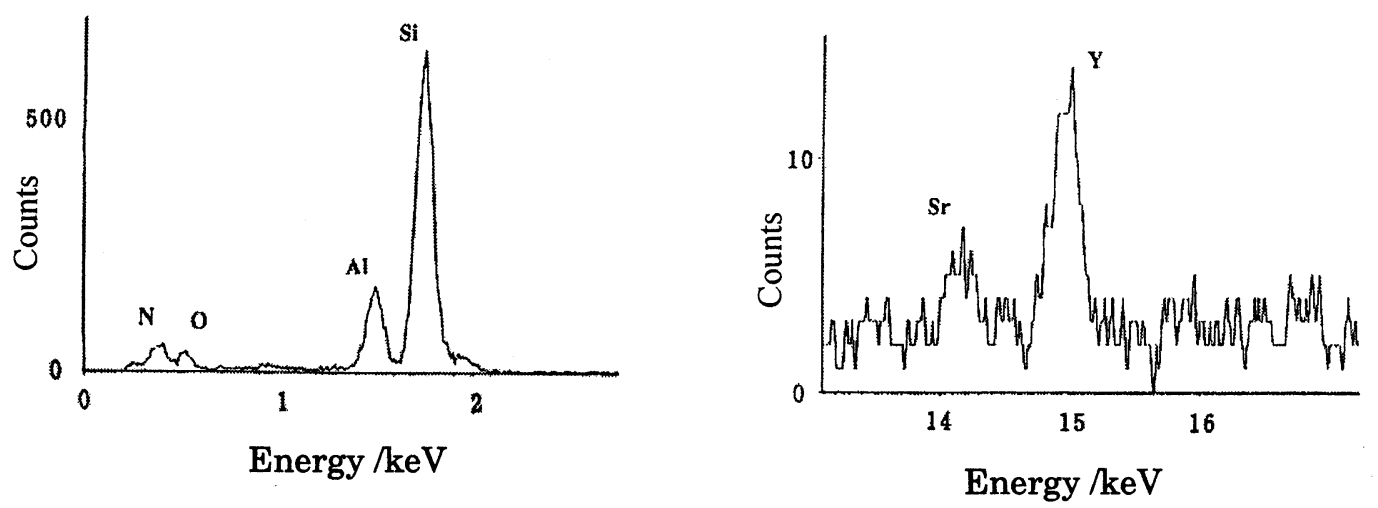

(a) Equiaxied Grain


(b) Anisotropic Grain

Fig. 4. Electron dispersive X-ray spectra of (a) equiaxied grain and (b) anisotropic grain.

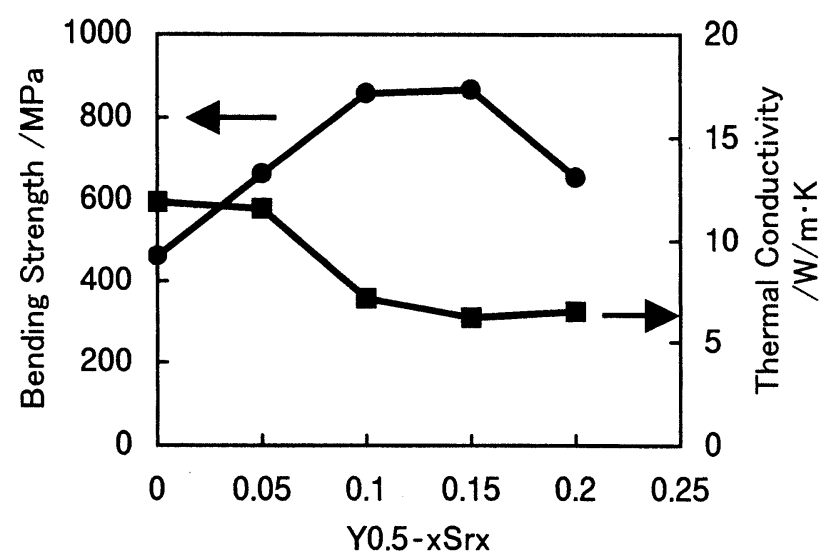

Fig. 5. Thermal conductivity and bending strength of Sr added $\mathrm{Y}-\alpha^{\prime}-\mathrm{SiA} 1 \mathrm{ON}$.

総合開発機構より委託を受けて行われたものである.

\section{文献}

1) Lange, F. F., Siebeneck, H. J. and Hasselman, D. P. H., J. Am. Ceram. Soc., 59, 454-55 (1976).

2) Kuriyama, M., Inomata, Y., Kijima, T. and Hasegawa, Y., Am. Ceram. Soc. Bull., 57, 1119-22 (1978).

3) Mitomo, M., Hirosaki, N. and Mitsuhashi, T., J. Mater. Sci.

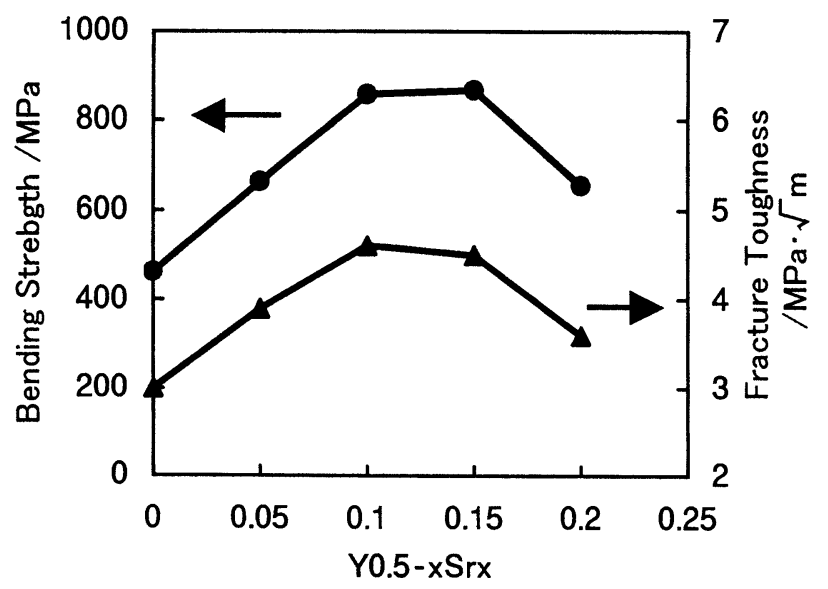

Fig. 6. Mechanical properties of Sr added Y- $\alpha^{\prime}-\mathrm{SiAlON}$.

Lett., 3, 915-16 (1984).

4) Liu, D.-M., Chen, C.-J. and Lee, R. R.-R., J. Appl. Phys., 77, 494-96 (1995).

5) Jack, K. H., J. Mater. Sci., 11, 1135-58 (1976).

6) Hampshire, S., Park, H. K., Thompson, D. P. and Jack, K. H., Nature, 274, 880 (1978).

7) Kingery, W. D., Bowen, H. K. and Uhlmann, D. R., "Introduction to Ceramics," Wiley-Interscience Publication (1960) pp. 621-24. 
8) Kobayashi, K., Kinouzairyo, 6, 1-9 (1980).

9) Huang, Z. K., Tien, T. Y. and Yen, T. S., J. Am. Ceram. Soc., 69, C241-42 (1986)

10) Sun, W. Y., Tien, T. Y. and Yen, T. S., Comm. Ceram. Soc., 74, 2547-50 (1991).

11) Jack, K. H., "Progress in Nitrogen Ceramics," Ed. by Riley, F. L., Martinus Nijhoff Publishers (1983) pp. 45-60.

12) Stutz, D., Greil, P. and Petzow, G., J. Mater. Sci. Lett., 5, 335-36 (1986).

13) Soderlund, E. and Ekstrom, T., J. Mater. Sci., 25, 4815-21 (1990).

14) Olsson, P. O., J. Mater. Sci., 24, 3878-87 (1989).

15) Ekstrom, T., Jansson, K., Olsson, P. O. and Persson, J., J. Eur. Ceram. Soc., 8, 3-9 (1991).
16) Mandal, H. and Thompson, D. P., J. Mater. Sci. Lett., 15, 1435-38 (1996).

17) Hwang, C. J., Susnitzky, D. W. and Beaman, D. R., J. Am. Ceram. Soc., 78, 588-92 (1995).

18) Watari, K., Seki, Y. and Ishizaki, K., J. Ceram. Soc. Japan (Seramikkusu Ronbunshi), 97, 174-81 (1989) [in Japanese].

19) Cheng, Y. B. and Thompson, D. P., J. Eur. Ceram. Soc., 14, 13-21 (1994).

20) Cheng, Y. B. and Thompson, D. P., J. Eur. Ceram. Soc., 14, 343-49 (1994).

21) Sun, W. Y., Yan, D. S., Gao, L., Mandal, H., Liddell, K. and Thompson, D. P., J. Eur. Ceram. Soc., 15, 349-55(1995).

22) Kishi, K. and Umebayashi S., J. Ceram. Soc. Japan, 102, 1086-90 (1994) [in Japanese]. 